\title{
Comprehensive genomic
}

\section{and phenotypic metal resistance profile of Pseudomonas putida strain S13.1.2 isolated from a vineyard soil}

Teik Min Chong ${ }^{1}$, Wai-Fong Yin ${ }^{1}$, Jian-Woon Chen ${ }^{1}$, Samuel Mondy ${ }^{2}$, Catherine Grandclément ${ }^{2}$, Denis Faure ${ }^{2}$, Yves Dessaux ${ }^{2}$ and Kok-Gan Chan ${ }^{1 *}$

\begin{abstract}
Trace metals are required in many cellular processes in bacteria but also induce toxic effects to cells when present in excess. As such, various forms of adaptive responses towards extracellular trace metal ions are essential for the survival and fitness of bacteria in their environment. A soil Pseudomonas putida, strain S13.1.2 has been isolated from French vineyard soil samples, and shown to confer resistance to copper ions. Further investigation revealed a high capacity to tolerate elevated concentrations of various heavy metals including nickel, cobalt, cadmium, zinc and arsenic. The complete genome analysis was conducted using single-molecule real-time (SMRT) sequencing and the genome consisted in a single chromosome at the size of $6.6 \mathrm{Mb}$. Presence of operons and gene clusters such as cop, cus, CzC, nik, and asc systems were detected and accounted for the observed resistance phenotypes. The unique features in terms of specificity and arrangements of some genetic determinants were also highlighted in the study. Our findings has provided insights into the adaptation of this strain to accumulation and persistence of copper and other heavy metals in vineyard soil environment.
\end{abstract}

Keywords: Pseudomonas putida, Single-molecule real-time (SMRT) sequencing, Vineyard soil, Copper resistance, Heavy metal resistance

\section{Introduction}

Natural or anthropogenic accumulation of heavy metals in the environment could be tenacious and exhibit toxicity towards living organisms. Though minute amounts of these metals (e.g. $\mathrm{Cu}, \mathrm{Ni}, \mathrm{Zn}$ ) are required in several cellular processes, excessive heavy metal ion concentrations can also exert deleterious effects by catalyzing oxidation of lipid membrane, damaging nucleic acids, and producing free radicals (Cánovas et al. 2003; Thounaojam et al. 2012; Wang et al. 2004). Consequently, presence of metal stress can alter the microbial composition and functional

\footnotetext{
*Correspondence: kokgan@um.edu.my

${ }^{1}$ Division of Genetics and Molecular Biology, Institute of Biological Sciences, Faculty of Science, University of Malaya, 50603 Kuala Lumpur, Malaysia

Full list of author information is available at the end of the article
}

diversity of microbial communities in relation with a decreased biomass of metal-sensitive microbes (Bardgett et al. 1994; Joynt et al. 2006; Kandeler et al. 1996). As such, it is likely that tolerant soil inhabitants acquired resistance systems towards a range of heavy metal found in soil environments, to maintain their fitness and survival capabilities. These resistance determinants, comprising operons or gene clusters, have been evidenced either in the chromosomes or plasmids of numerous Gram-positive and Gram-negative bacteria (GarcíaDomínguez et al. 2000; Karelová et al. 2011; Wang and Chen 2006).

Among the wide diversity of resistance mechanisms found in prokaryotes, the extrusion of cations, driven by transmembrane efflux pumps are well described. This includes, for instance, resistance-nodulation-cell division 
(RND) superfamily proteins that form complexes with (i) outer membrane factors (OMF) or (ii) membrane fusion proteins. These two complexes are involved in transport of heavy metal ions from cytoplasm to periplasm, or across outer membrane from periplasm to outside of the cell (Nies 2003). This phenomenon is exemplified by the CzcCBA system that mediates an efflux of $\mathrm{Co}^{2+}, \mathrm{Zn}^{2+}$ and $\mathrm{Cd}^{2+}$ ions (Nies 2000). Another family of heavy metal transport protein, namely P-type ATPases, are involved in both import of inorganic cations to cytoplasm from periplasm or outside of the cell, and export of these ions from/to cytoplasm in a reversed manner. Such mechanism requires ATP hydrolysis. The reported heavy metal substrates for this system include $\mathrm{Cu}^{2+}, \mathrm{Ag}^{+}, \mathrm{Cd}^{2+}$ and $\mathrm{Zn}^{2+}$ (Fagan and Saier 1994). Aside from ion transport, detoxification of heavy metal ions is also essential for bacteria. For instance, reduction of the pentavalent arsenate $[\mathrm{As}(\mathrm{V})]$ ion to its trivalent arsenite $[\mathrm{As}(\mathrm{III})]$ counterpart by the arsenate reductase ArsC enables the detoxification and efflux of As(III) through the membrane pump protein ArsB (Cai et al. 1998; Carlin et al. 1995). In addition, these systems are often regulated in response to the presence of metal ions that in turn activates transcription of subsequent resistance determinants. Examples include the regulator ArsR that induces the expression of the ars arsenite/antimonite resistance operon upon exposure to these ions (Sato and Kobayashi 1998), or CzcD, a cation diffusion facilitator protein that partially regulates the expression of the CzcCBA system (Nies 1992).

Copper-containing pesticides have long been used, primarily for the control of plant pathogens and associated diseases especially in vineyards (Cooksey 1993). Indeed, Vitis vinifera is a non-rotating grape crop that has been routinely treated with copper sulphate over the years in order to control fungal diseases (Andreazza et al. 2010). Consequently, such anthropogenic accumulation of copper selects for the prevalence of copper resistant microorganisms that carry the genetic determinants involved in acquisition, efflux, sequestration or cellular distribution of copper (Andreazza et al. 2010; Cervantes and Gutierrez-Corona 1994; Munson et al. 2000). This feature has sparked interest to identify the microbiota inhabiting these soils and the abilities to tolerate elevated amount of copper ions as well as that of other heavy metal ions. Here, we described the heavy metal resistance phenotypes of Pseudomonas putida strain S13.1.2 isolated from a vineyard in France and the profile of possible genetic determinants responsible for metal resistance was also reported in the study.

\section{Materials and methods}

\section{Sampling and bacteria isolation}

In this study, strain S13.1.2 was isolated from a vineyard soil sample obtained in Riquewihr, France. Collection of soil sample was performed at subsurface level (to the depth of $5 \mathrm{~cm}$ ). Isolation of this strain was performed using KG medium supplemented with $500 \mathrm{mg} / \mathrm{L} N$-heptanoyl-homoserine lactone as sole carbon and nitrogen source (Chan et al. 2009). Next, the strain was identified using both 16S rRNA gene sequencing analysis using 27F (5'-AGAGTTTGATCMTGGCTCAG-3') (Lane 1991) and 1525R (5'-AAGGAGGTGWTCCARCC-3') (Dewhirst et al. 2000) primers pair followed by Microflex MALDI-TOF (Bruker Daltonik GmbH, Leipzig, Germany) bench-top mass spectrometer (Chen et al. 2013). The pure culture was routinely maintained on LB (LuriaBertani, Merck, Whitehouse Station, NJ, USA) agar at $28^{\circ} \mathrm{C}$ or cultivated in LB broth agitated at $220 \mathrm{rpm}$.

\section{Copper tolerance assay}

Maximum tolerable concentration of copper sulphate salt $\left(\mathrm{CuSO}_{4}\right)$ for the growth of $P$. putida S13.1.2 was determined. To do so, $1 \mu \mathrm{L}$ of an overnight culture was inoculated into $200 \mu \mathrm{L}$ of LB broth supplemented with different concentrations of $\mathrm{CuSO}_{4}$ ranging from 0 to $5 \mathrm{mM}$ and placed into a 96-wells microtitre plate. The growth curves of the strain were monitored at $\mathrm{OD}_{600}$ with measurements taken at the interval of $30 \mathrm{~min}$ for 24 h using a Tecan Infinite M200 luminometer (Tecan, Mannerdorf, Switzerland).

\section{Biolog phenotype microarray analysis}

The phenotypes associated with the heavy metal resistance of strain S13.1.2 were assessed using biolog phenotype microarray analysis. The overnight cultured bacterial colonies were inoculated into Biolog IF-0a GN/GP Base medium to reach $85 \%$ turbidity followed by 1:200 dilution aliquoted into IF-10b medium supplemented with Dye Mix A as indicated by the manufacturer instructions. The mixture were then added into wells of Biolog Microplates PM13B, PM14A, PM15B, PM16A and PM18C containing substrates of various heavy metal salts. The incubation and growth of inocula were monitored for $96 \mathrm{~h}$ with readings taken at $15 \mathrm{~min}$ intervals. Growth of bacteria in the presence of heavy metals causes reduction of the dye, resulting in purple colour formation. The kinetic information were recorded and quantified (Bochner et al. 2001) using OmniLog OL_FM_12 kinetic software (Biolog, USA) for data analysis and export. 


\section{Genomic DNA preparation and complete genome sequencing}

Bacterial genomic DNA was extracted using MasterPure $^{\mathrm{TM}}$ Complete DNA and RNA Purification Kit (Epicentre, Illumina Inc., Madison, Wisconsin) according to the manufacturer instructions. The purity of DNA was examined using a NanoDrop spectrophotometer (Thermo Scientific, Waltham, MA, USA) and agarose gel electrophoresis. DNA quantification was carried out with a Qubit ${ }^{\circledR} 2.0$ fluorometer (dsDNA Broad Range Assay Kit, Invitrogen, Carlsbad, CA, USA). The genome of strain S13.1.2 was sequenced using a PacBio RSII platform. Prior to sequencing, the preparation of the DNA library was performed using a Template Preparation Kit (Pacific Biosciences, Inc., CA) with fragments size targeted at $10 \mathrm{~kb}$. For completion sequencing of the genome, sequence collection was carried out in 7 SMRT cells using P4/C2 chemistry for $180 \mathrm{~min}$ for each cell.

\section{Genome assembly and annotation}

The acquired sequence reads were subjected to quality filtering and de novo assembly using the hierarchical genome-assembly process (HGAP) version 3.0 module available from the Pacific Biosciences's SMRT portal (Chin et al. 2013). Circularization of the genome was verified using Gepard version 1.30 (Krumsiek et al. 2007) followed by curation using to Amos (http://www.amos. sourceforge.net/wiki/index.php/ToAmos) and minimus2 (http://www.amos.sourceforge.net/wiki/index.php/Minimus2) programs. The genes in the assembled sequences were then predicted and annotated using Rapid Prokaryotic Genome Annotation (Prokka) (Seemann 2014). Open reading frames attributed to heavy metal resistance were additionally validated by sequence comparison with NCBI-NR using BLAST program. The genome of $P$. putida S13.1.2 was also deposited at the integrated microbial genome (IMG) platform (http://www.img. jgi.doe.gov/) for additional gene prediction and manual functional annotation (Markowitz et al. 2012).

\section{Accession number}

The complete genome sequence has been also deposited at NCBI under accession number CP010979. The P. putida strain S13.1.2 is available at DSMZ (accession no. DSM 102034).

\section{Results}

\section{Isolation and characterization of strain S13.1.2}

Sequence comparison with GenBank databases using the BLASTN followed by phylogenetic analysis revealed the closest identified relative to P. putida NBRC 14164 sharing $99 \%$ of sequence identity (Additional file 1: Figure

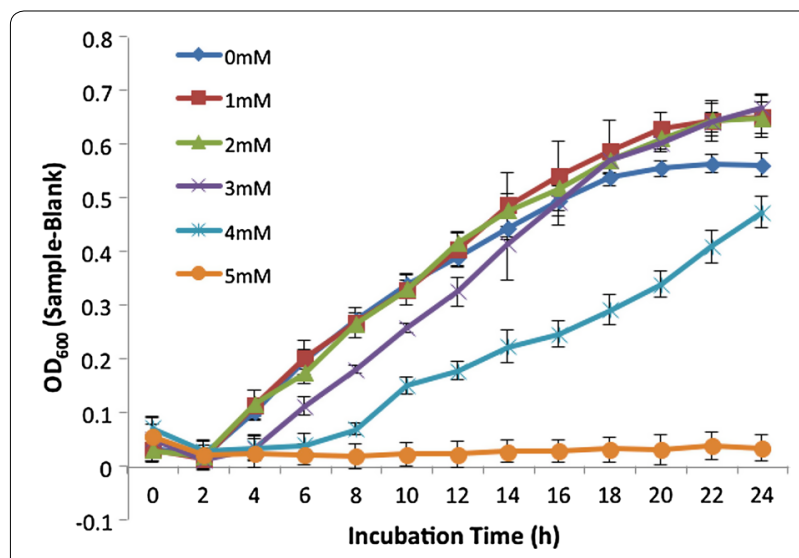

Fig. 1 The growth curve of strain S13.1.2 in various copper sulphate salt $\left(\mathrm{CuSO}_{4}\right)$ concentrations monitored for $24 \mathrm{~h}$. The graphs represent mean results from $\left(\mathrm{OD}_{600}\right.$ - blank) values of triplicate cultures with error bars signifying standard deviations $(n=3)$. Growth was observed at up to $4 \mathrm{mM}$ of $\mathrm{CuSO}_{4}$ supplemented into the culture medium

S1). Additional identification using MALDI-TOF-MS analysis also showed coherent identification of $P$. putida as the closest relative with matching score constantly above the values of 1.9 .

\section{Copper resistance and other heavy metal resistance traits of strain $\mathrm{S} 13.1 .2$}

Growth of P. putida S13.1.2 in the presence of various $\mathrm{CuSO}_{4}$ concentrations in LB medium was observed in media supplemented with up to $3.5 \mathrm{mM}$ of the copper salt. Though with a slightly hindered growth, strain S13.1.2 was also able to grow in $4 \mathrm{mM}$ of $\mathrm{CuSO}_{4}$ (Fig. 1). The capability of S13.1.2 to tolerate different heavy metals was determined via biolog phenotype microarray analysis. After the incubation time of $96 \mathrm{~h}$, complete growth curves were observed in the presence of almost all tested heavy metal salts (Table 1). Such observations prompted us to search for genetic determinants involved in copper resistant ability of this strain.

\section{Genome properties}

HGAP assembly and circularization of the genome of P. putida S13.1.2 has yielded a single contig with a final assembled genome size of 6621,848 bp and a sequencing depth of 163.56 -fold. This led us to conclude that the genome of P. putida S13.1.2 consisted in one circular chromosome with a $62.34 \% \mathrm{G}+\mathrm{C}$ content (Additional file 1: Table S2). As displayed in the IMG/ER gene prediction and annotation, 5979 genes were predicted, 5814 (97.24 \%) of which being protein-coding genes. An amount of 4923 genes among the protein coding genes 
Table 1 Growth of Pseudomonas strain S13.1.2 in presence of various heavy metal salts from PM13B, PM14A, PM15B, PM16A and PM18C

\begin{tabular}{lll}
\hline Biolog microplates & Heavy metal salt & Growth observed \\
\hline PM13B & $\mathrm{NiCl}_{2}$ & +++ \\
& $\mathrm{K}_{2} \mathrm{CrO}_{4}$ & ++ \\
& $\mathrm{CsCl}$ & ++++ \\
& $\mathrm{CoCl}_{2}$ & +++ \\
& $\mathrm{MnCl}_{2}$ & ++ \\
& $\mathrm{CuCl}_{2}$ & ++++ \\
& $\mathrm{CdCl}_{2}$ & ++ \\
PM14A & $\mathrm{NaAsO}_{3}$ & ++++ \\
& $\mathrm{ZnCl}_{2}$ & ++++ \\
PM15B & $\mathrm{NaSeO}_{3}$ & ++ \\
PM16A & $\mathrm{CrCl}_{3}$ & ++++ \\
& $\mathrm{NaAsO}_{2}$ & +++ \\
PM18C & $\mathrm{SbCl}_{3}$ & - \\
& $\mathrm{Scfin}$ &
\end{tabular}

Heavy metal resistance profile is defined by bacterial growth measured after $96 \mathrm{~h}$ in phenotype microarray microplates wells containing four different concentrations of each heavy metal salts. The extent of growth observed were indicated as ++++ (full growth),+++ (strong), ++ (moderate), + (weak) and - (sensitive) signs

Table 2 Nucleotide content and gene count levels of the genome predicted in IMG/ER

\begin{tabular}{lcl}
\hline Attribute & \multicolumn{2}{l}{ Genome (total) } \\
\cline { 2 - 3 } & Value & \% of total ${ }^{\mathbf{a}}$ \\
\hline Size (bp) & $6,621,848$ & 100 \\
G + C content (bp) & $4,128,086$ & 62.34 \\
Coding region (bp) & $5,922,241$ & 89.43 \\
Total genes & 5979 & 100 \\
RNA genes & 165 & 2.76 \\
Protein-coding genes & 5814 & 97.24 \\
Genes in paralog clusters & 4841 & 80.97 \\
Genes assigned to CoGs & 4343 & 72.64 \\
Genes with signal peptides & 643 & 10.75 \\
Genes with transmembrane helices & 1324 & 22.14 \\
Paralogous groups & 0 & - \\
Pseudogenes & 0 & - \\
\hline
\end{tabular}

a The total is based on either the size of the genome in base pairs or the total number of protein coding genes in the annotated genome

were assigned with putative functions with the remaining 891 genes predicted as hypothetical proteins. In addition, 165 RNA genes were predicted with 22 genes assigned as rRNA and 75 genes as tRNA. The properties and the statistics of the genome are summarized in Table 2. The genomic features were also presented in IMG/ER database (https://www.img.jgi.doe.gov/cgi-bin/ mer $/$ main.cgi?section $=$ TaxonDetail $\&$ page $=$ taxonDetail \&taxon_oid=2609459728).
In silico identification of copper resistance genes

A total of 18 putative copper resistance genes, orthologous to genes associated with copper homeostasis and copper transport, were identified at six locations of the P. putida strain S13.1.2 genome (Fig. 2; Additional file 1: Table S1). For transport of copper ions, the genetic determinants cop $A 2$ and cop $A 3$ encoding copper-importing P-type ATPase A and copper-exporting P-type ATPase $A$, respectively, were identified. Besides, a gene cluster composed of $\operatorname{cop} B 1, m c o$, and $\operatorname{cop} A 1$ that encode copper resistance protein $B$, multicopper oxidase and copper resistance protein $\mathrm{A}$, respectively was also present.

Aside from cop genes, a gene cluster consisting in cusA1, cusA 2 and $c u s B$ that coded cation efflux system proteins and $c u s F$ that coded a copper binding periplasmic protein were present. All these genes were components of a putative operon ( $c u s C F B A$ ) that determined an efflux pump for copper and silver ions. However genes encoding the CusC outer membrane channel component, belonging to OMF family was absent (Kulathila et al. 2011). Instead, the outer membrane efflux protein located upstream of CusB gene showed higher similarity towards TolC, another OMF that is described as part of the AcrAB-TolC multidrug efflux pump system (Balakrishnan et al. 2001; Rensing and Grass 2003). Although TolC was shown not to restore metal resistance in CusC knockouts in Escherichia coli (Franke et al. 2003), such a combination might represent a new copper transport mechanism in P. putida.

\section{Genetic determinants for other heavy metal resistance}

Following the phenotype microarray analysis that revealed resistance towards various heavy metals, a series of determinants were also identified in the genome of S13.1.2 (Fig. 2; Additional file 1: Table S1). The genes that likely contributed to resistance traits included the $n i k R A B C D E$ putative operon that mediated uptake of nickel ions, in which $n i k R$ negatively regulates the expression when in excess of nickel ions (Chivers and Sauer 2000; Navarro et al. 1993).

Aside, a gene cluster that grouped $c z c$ cobalt-zinc-cadmium resistance determinants was found. $\mathrm{CzcC}, \mathrm{CzcB}$ and $\mathrm{CzcA}$ heavy metal efflux proteins are involved in the efflux of heavy metals ions such as $\mathrm{Co}^{2+}, \mathrm{Cd}^{2+}$ and $\mathrm{Zn}^{2+}$ (Nies 1992, 2000). The deduced CzcA, CzcB and CzcC proteins of $P$. putida strain $\mathrm{S} 13.1 .2$ belonged to the family of $\mathrm{CzcA}, \mathrm{CzcB}$ and $\mathrm{CzcC}$ heavy metal RND efflux proteins in the $P$. putida group. A $c z c D$ gene involved in the repression of $c z c$ system was also present in the genome (Anton et al. 1999; van der Lelie et al. 1997).

Strain S13.1.2 also appeared to be highly resistant towards As(V) salt (microplate PM14A) and moderately towards As(III) salt (microplate PM18C). The genome 


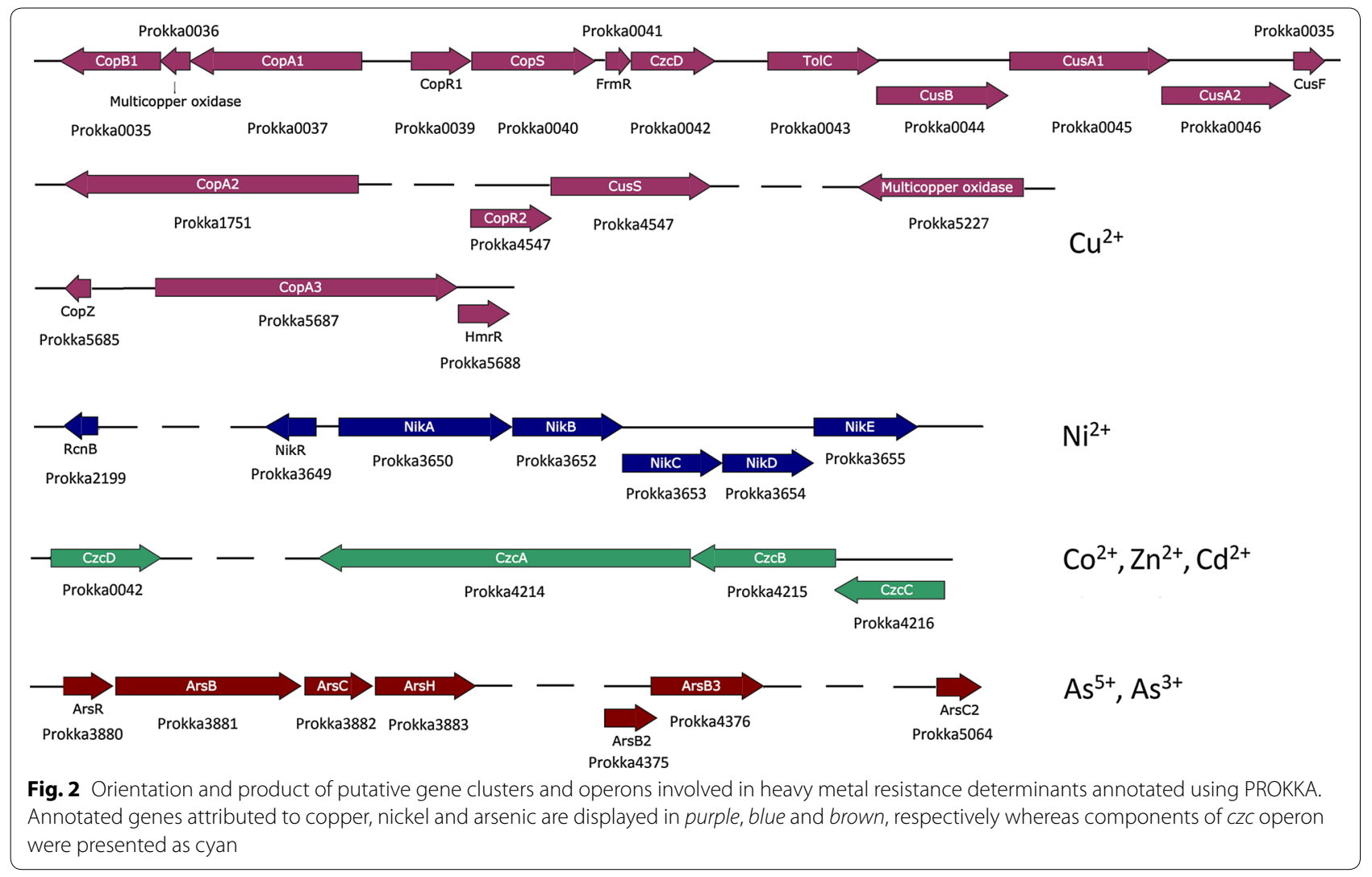

sequence revealed the presence of an arsenate resistance operon (ars) that consisted in $\operatorname{ars} R$, $\operatorname{arsB} 1, \operatorname{ars} C 1$ and ars $H$ determinants, together with arsB2, ars $B 3$ and ars $C 2$ genes at different locations in the genome.

\section{Discussion}

The genome sequence of $P$. putida strain S13.1.2 isolated from a vineyard soil revealed that it contained a series of cop and cus genes associated with noticeable in vivo resistance to copper in this study. Identification of cop genes strongly suggested the occurrence of a resistance mechanism based on protein-mediated sequestration and cellular accumulation of the copper ions in the cell (Cooksey 1993). Notably, it is also highly possible that the transport of copper is further facilitated by cus operon. Activation of this transport mechanism is likely mediated by the copR 1 and $\operatorname{cop} S$ genes located upstream of the cus gene cluster that encodes the transcriptional activator and sensor kinase. In Pseudomona syringae, this pair forms a two-component regulatory system whereby phosphorylation of CopR by CopS induces the expression of the copper resistance operon (Mills et al. 1993). Another set of transcriptional activator and sensor kinase genes (copR2 and cusS) was also found in the genome. However sequence alignments between both gene pairs showed a low identity $(52.9 \%)$ and similarity $(66.1 \%)$ at the protein level that suggested their involvement in dissimilar copper resistance mechanisms.

The copper resistant trait of this strain could also be discussed in the light of a reported result where another copper resistant Pseudomonas strain was also isolated from the same environment, namely $P$. mendocina strain S5.2. The genome of P. mendocina strain S5.2 also harbors genes that encode proteins predicted to be involved in heavy-metal transport/detoxification and heavy-metal resistance such as heavy-metal-translocating P-type ATPases, known for their role in heavy metal ion homeostasis and biotolerance of heavy-metal ions (e.g. $\mathrm{Cu}^{2+}$, $\mathrm{Cd}^{2+}, \mathrm{Zn}^{2+}$, and $\mathrm{Ag}^{+}$) (Chong et al. 2012). Furthermore, these bacteria are part of the grapevine endophytic microbiome and are frequently detected in vineyard soils (Salomon et al. 2014; West et al. 2010). In addition to this, pseudomonads often exhibit elevated copper resistance (Andreazza et al. 2012).

As concentrations up to $1000 \mathrm{mg}$ copper sulphate per $\mathrm{kg}$ soil can still be found in some places (Flores-Vélez et al. 1996) and surface layer of soil poses the highest level of copper as reported by Angelova et al. (1999) isolation of Pseudomonas strains at this depth $(5 \mathrm{~cm})$ hereby 
corresponds to the copper resistance traits. Therefore, anthropogenic accumulation of copper likely explains the prevalence of Pseudomonas that could support the growth of plants treated with copper sulphate over the years in order to control fungal diseases.

Furthermore the presence of $n i k, c z c$ and ars operons in the genome that corresponds to resistance phenotypes towards their respective heavy metals also drove speculation on the tenacity of other vineyard soil chemistries in this study. Of note, vineyards have also been treated with sodium arsenate till the end of the last century, and vineyard posts in several parts of the world have been treated with a mixture of copper-chromium-arsenic salts. As a consequence, chromium and arsenic salts in vineyards soils and surrounding fields may remain at detectable concentrations [e.g. (Robinson et al. 2006)]. Hence identification of ars operon and resistance in this strain indicates the persistence of arsenic in this vineyard soil environment.

The ars operons are quite diverse (Branco et al. 2008) in pseudomonads such as $P$. aeruginosa (Cai et al. 1998) and P. putida (Fernández et al. 2014). In response to the presence of arsenite, the transcriptional repressor ArsR bound to the cognate promoter is released, followed by the subsequent induction of the ars gene expression (Busenlehner et al. 2003; Murphy and Saltikov 2009). These include the transmembrane efflux pump ArsB that extrudes arsenite and the arsenate reductase ArsC that converts $\mathrm{As}(\mathrm{V})$ to $\mathrm{As}(\mathrm{III})$, this later being readily transported out of the cell by ArsB (Cai et al. 1998; Jackson and Dugas 2003). To date, no defined functions were assigned to the NADPH-dependent FMN reductase ArsH. It was suggested to respond to the oxidative stress caused by arsenite and recently, ArsH been demonstrated to oxidize trivalent organoarsenical herbicides to pentavalent species (Chen et al. 2015; Hervás et al. 2012). Intriguingly, since ars determinants are responsible for both arsenic and antimony $(\mathrm{Sb})$ resistance (Branco et al. 2008; Cai et al. 1998; Carlin et al. 1995), strain S13.1.2 was tested for resistance to $\mathrm{Sb}(\mathrm{III})$ salt and found to be sensitive. This may imply a single substrate specificity of $P$. putida strain S13.1.2 ArsR protein towards arsenic and it is also possible that presence of $\mathrm{As}(\mathrm{III})$ is required to confer resistance to $\mathrm{Sb}$ (III).

As concluding remarks, our findings has demonstrated the versatility and adaptation of $P$. putida strain S13.1.2 to the grapevine, copper rich soils and towards the persistent effect of the soil contamination by some heavy metals on the resident microbiota. The comprehensive profiling of heavy metal resistance features also demonstrated this strain as potential tool for bioremediation procedures on vineyard or crop related soils.

\section{Additional file}

Additional file 1. Additional figures and table.

\section{Abbreviations}

Ag: silver; As: arsenic; Cs: cesium; Cd: cadmium; Cl: chloride; Co: cobalt; Cu: copper; K: potassium; Na: sodium; Ni: nickel; Sb: antimony; Zn: zinc; RND: resistance-nodulation-cell division; OMF: outer membrane factors.

\section{Authors' contributions}

TMC, JC, WY, and CG performed the phenotypic microarray and complete sequencing experiments. Bioinformatics analysis was carried out by TMC and $S M$ while $Y D, D F$, and $K C$ conceived the idea and obtained funding for the project. All authors prepared and proofread the final draft. All authors read and approved the final manuscript.

\section{Author details}

${ }^{1}$ Division of Genetics and Molecular Biology, Institute of Biological Sciences, Faculty of Science, University of Malaya, 50603 Kuala Lumpur, Malaysia. ${ }^{2}$ Institute for Integrative Biology of the Cell (I2BC), CEA, CNRS, Université Paris-Sud, Université Paris-Saclay, 91198 Gif-sur-Yvette, France.

\section{Acknowledgements}

TMC, KGC and YD would like to thank The French Embassy in Malaysia for the awarded fellowships and continuous support.

\section{Competing interests}

The authors declare that they have no competing interests.

\section{Funding}

This research was supported by the University of Malaya through HIR Grants awarded to KG Chan (UM-MOHE HIR Grant UM C/625/1/HIR/MOHE/ CHAN/14/1, no. H-50001-A000027; UM-MOHE HIR Grant UM C/625/1/HIR/ MOHE/CHAN/01, no. A000001-50001); Postgraduate Research Grant (PPP) awarded to TM Chong (Grant no. PG080-2015B).

Received: 11 August 2016 Accepted: 4 October 2016

Published online: 12 October 2016

\section{References}

Andreazza R, Pieniz S, Wolf L, Lee MK, Camargo FAO, Okeke BC (2010) Characterization of copper bioreduction and biosorption by a highly copper resistant bacterium isolated from copper-contaminated vineyard soil. Sci Total Environ 408:1501-1507

Andreazza R, Okeke BC, Pieniz S, Camargo FAO (2012) Characterization of copper-resistant rhizosphere bacteria from Avena sativa and Plantago lanceolata for copper bioreduction and biosorption. Biol Trace Elem Res 146:107-115

Angelova V, Ivanov A, Braikov D, Ivanov K (1999) Heavy metal (Pb, Cu, Zn and (d) content in wine produced from grape cultivar Mavrud, grown in an industrially polluted region. J Int Sci Vigne Vin 33:119-131

Anton A, Große C, Reißmann J, Pribyl T, Nies DH (1999) CzcD is a heavy metal ion transporter involved in regulation of heavy metal resistance in Ralstonia sp. strain CH34. J Bacteriol 181:6876-6881

Balakrishnan L, Hughes C, Koronakis V (2001) Substrate-triggered recruitment of the TolC channel-tunnel during type I export of hemolysin by Escherichia coli. J Mol Biol 313:501-510

Bardgett RD, Speir TW, Ross DJ, Yeates GW, Kettles HA (1994) Impact of pasture contamination by copper, chromium, and arsenic timber preservative on soil microbial properties and nematodes. Biol Fertil Soils 18:71-79

Bochner BR, Gadzinski P, Panomitros E (2001) Phenotype microarrays for highthroughput phenotypic testing and assay of gene function. Genome Res 11:1246-1255 
Branco R, Chung A-P, Morais PV (2008) Sequencing and expression of two arsenic resistance operons with different functions in the highly arsenicresistant strain Ochrobactrum tritici SCII24T. BMC Microbiol 8:95

Busenlehner LS, Pennella MA, Giedroc DP (2003) The SmtB/ArsR family of metalloregulatory transcriptional repressors: structural insights into prokaryotic metal resistance. FEMS Microbiol Rev 27:131-143

Cai J, Salmon K, DuBow MS (1998) A chromosomal ars operon homologue of Pseudomonas aeruginosa confers increased resistance to arsenic and antimony in Escherichia coli. Microbiology 144:2705-2729

Cánovas D, Cases I, de Lorenzo V (2003) Heavy metal tolerance and metal homeostasis in Pseudomonas putida as revealed by complete genome analysis. Environ Microbiol 5:1242-1256

Carlin A, Shi W, Dey S, Rosen BP (1995) The ars operon of Escherichia coli confers arsenical and antimonial resistance. J Bacteriol 177:981-986

Cervantes C, Gutierrez-Corona F (1994) Copper resistance mechanisms in bacteria and fungi. FEMS Microbiol Rev 14:121-137

Chan KG, Yin WF, Sam CK (2009) Koh CL (2009) A novel medium for the isolation of $\mathrm{N}$-acylhomoserine lactone-degrading bacteria. J Ind Microbiol Biot 36:247-251

Chen JW, Koh CL, Sam CK, Yin WF, Chan KG (2013) Short chain N-acyl homoserine lactone production by soil isolate Burkholderia sp. strain A9. Sensors 13:13217-13227

Chen J, Bhattacharjee H, Rosen BP (2015) ArsH is an organoarsenical oxidase that confers resistance to trivalent forms of the herbicide monosodium methylarsenate and the poultry growth promoter roxarsone. Mol Microbiol 96:1042-1052

Chin CS, Alexander DH, Marks P, Klammer AA, Drake J, Heiner C, Clum A, Copeland A, Huddleston J, Eichler EE, Turner SW, Korlach J (2013) Nonhybrid, finished microbial genome assemblies from long-read SMRT sequencing data. Nat Methods 10:563-569

Chivers PT, Sauer RT (2000) Regulation of high affinity nickel uptake in bacteria $\mathrm{Ni}^{2+}$-dependent interaction of NikR with wild-type and mutant operator sites. J Biol Chem 275:19735-19741

Chong TM, Yin WF, Mondy S, Grandclément C, Dessaux Y, Chan KG (2012) Heavy-metal resistance of a france vineyard soil bacterium, Pseudomonas mendocina strain S5.2, revealed by whole-genome sequencing. J Bacteriol 194:6366

Cooksey DA (1993) Copper uptake and resistance in bacteria. Mol Microbiol $7: 1-5$

Dewhirst F, Tamer M, Ericson R, Lau C, Levanos V, Boches S, Galvin J, Paster B (2000) The diversity of periodontal spirochetes by $16 \mathrm{~S}$ rRNA analysis. Oral Microbiol Immunol 15:196-202

Fagan MJ, Saier MH Jr (1994) P-type ATPases of eukaryotes and bacteria: sequence analyses and construction of phylogenetic trees. J Mol Evol 38:57-99

Fernández M, Udaondo Z, Niqui JL, Duque E, Ramos JL (2014) Synergic role of the two ars operons in arsenic tolerance in Pseudomonas putida KT2440. Environ Microbiol Rep 6:483-489

Flores-Vélez LM, Ducaroir J, Jaunet AM, Robert M (1996) Study of the distribution of copper in an acid sandy vineyard soil by three different methods. Eur J Soil Sci 47:523-532

Franke S, Grass G, Rensing C, Nies DH (2003) Molecular analysis of the copper-transporting efflux system CusCFBA of Escherichia coli. J Bacteriol 185:3804-3812

García-Domínguez M, Lopez-Maury L, Florencio FJ, Reyes RC (2000) A gene cluster involved in metal homeostasis in the cyanobacterium Synechocystis sp. strain PCC 6803. J Bacteriol 182:1507-1514

Hervás M, López-Maury L, León P, Sánchez-Riego AM, Florencio FJ, Navarro JA (2012) Ars H from the cyanobacterium Synechocystis sp. PCC 6803 is an efficient NADPH-dependent quinone reductase. Biochem 51:1178-1187

Jackson CR, Dugas SL (2003) Phylogenetic analysis of bacterial and archaeal ars $C$ gene sequences suggests an ancient, common origin for arsenate reductase. BMC Evol Biol 3:18

Joynt J, Bischoff M, Turco R, Konopka A, Nakatsu CH (2006) Microbial community analysis of soils contaminated with lead, chromium and petroleum hydrocarbons. Microb Ecol 51:209-219
Kandeler F, Kampichler C, Horak O (1996) Influence of heavy metals on the functional diversity of soil microbial communities. Biol Fertil Soils 23:299-306

Karelová E, Harichová J, Stojnev T, Pangallo D, Ferianc P (2011) The isolation of heavy-metal resistant culturable bacteria and resistance determinants from a heavy-metal-contaminated site. Biologia 66:18-26

Krumsiek J, Arnold R, Rattei T (2007) Gepard: a rapid and sensitive tool for creating dotplots on genome scale. Bioinformatics 23:1026-1028

Kulathila R, Kulathila R, Indic M, van den Berg B (2011) Crystal structure of Escherichia coli CusC, the outer membrane component of a heavy metal efflux pump. PLoS One 6:e15610

Lane DJ (1991) 16S/23S rRNA sequencing. In: Stackebrandt E, Goodfellow M (eds) Nucleic acids techniques in bacterial systematics. Wiley, Chichester, pp 115-147

Markowitz VM, Chen I-MA, Palaniappan K, Chu K, Szeto E, Grechkin Y, Ratner A, Jacob B, Huang J, Williams P, Huntemann M, Anderson I, Mavromatis K, Ivanova NN, Kyrpides NC (2012) IMG: the integrated microbial genomes database and comparative analysis system. Nucleic Acids Res 40:D115-D122

Mills SD, Jasalavich CA, Cooksey DA (1993) A two-component regulatory system required for copper-inducible expression of the copper resistance operon of Pseudomonas syringae. J Bacteriol 175:1656-1664

Munson GP, Lam DL, Outten FW, O'Halloran TV (2000) Identification of a copper-responsive two-component system on the chromosome of Escherichia coli K-12. J Bacteriol 182:5864-5871

Murphy JN, Saltikov CW (2009) The ArsR repressor mediates arsenite-dependent regulation of arsenate respiration and detoxification operons of Shewanella sp. strain ANA-3. J Bacteriol 191:6722-6731

Navarro C, Wu LF, Mandrand-Berthelot MA (1993) The nik operon of Escherichia coli encodes a periplasmic binding-protein-dependent transport system for nickel. Mol Microbiol 9:1181-1191

Nies DH (1992) Resistance to cadmium, cobalt, zinc, and nickel in microbes. Plasmid 27:17-28

Nies DH (2000) Heavy metal-resistant bacteria as extremophiles: molecular physiology and biotechnological use of Ralstonia sp. CH34. Extremophiles 4:77-82

Nies DH (2003) Efflux-mediated heavy metal resistance in prokaryotes. FEMS Microbiol Rev 27:313-339

Rensing C, Grass G (2003) Escherichia coli mechanisms of copper homeostasis in a changing environment. FEMS Microbiol Rev 27:197-213

Robinson B, Greven M, Green S, Sivakumaran S, Davidson P, Clothier B (2006) Leaching of copper, chromium and arsenic from treated vineyard posts in Marlborough, New Zealand. Sci Total Environ 364:113-123

Salomon MV, Bottini R, de Souza Filho GA, Cohen AC, Moreno D, Gil M, Piccoli $P$ (2014) Bacteria isolated from roots and rhizosphere of Vitis vinifera retard water losses, induce abscisic acid accumulation and synthesis of defense-related terpenes in in vitro cultured grapevine. Physiol Plant 151:359-374

Sato T, Kobayashi Y (1998) The ars operon in the skin element of Bacillus subtilis confers resistance to arsenate and arsenite. J Bacteriol 180:1655-1661

Seemann T (2014) Prokka: rapid prokaryotic genome annotation. Bioinformatics. doi:10.1093/bioinformatics/btu153

Thounaojam TC, Panda P, Mazumdar P, Kumar D, Sharma GD, Sahoo L, Panda SK (2012) Excess copper induced oxidative stress and response of antioxidants in rice. Plant Physiol Biochem 53:33-39

van der Lelie D, Schwuchow T, Schwidetzky U, Wuertz S, Baeyens W, Mergeay M, Nies DH (1997) Two-component regulatory system involved in transcriptional control of heavy-metal homoeostasis in Alcaligenes eutrophus. Mol Microbiol 23:493-503

Wang J, Chen C (2006) Biosorption of heavy metals by Saccharomyces cerevisiae: a review. Biotech Adv 24:427-451

Wang SH, Yang ZM, Yang H, Lu B, Li SQ, Lu YP (2004) Copper-induced stress and antioxidative responses in roots of Brassica juncea L. Bot Bull Acad Sin 45:203-212

West ER, Cother EJ, Steel CC, Ash GJ (2010) The characterization and diversity of bacterial endophytes of grapevine. Can J Microbiol 56:209-216 